Tohoku J. Exp. Med., 2010, 221, 221-227

\title{
Tail-Suspended Mice Lacking Calponin H1 Experience Decreased Bone Loss
}

\author{
Naoki Yotsumoto, ${ }^{1}$ Michiko Takeoka ${ }^{2}$ and Minesuke Yokoyama ${ }^{3}$
}

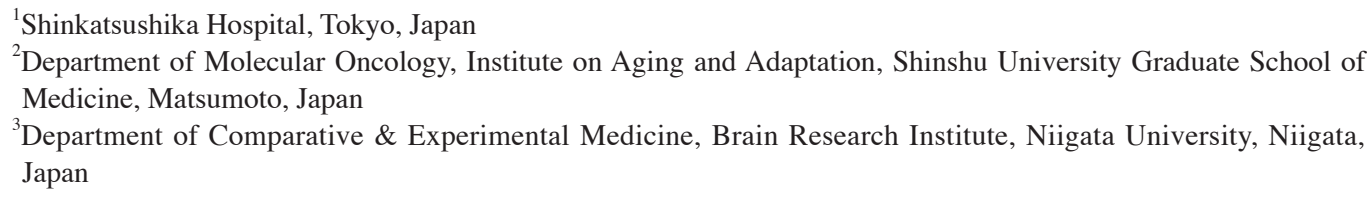

Calponin h1 (CNh1) is an actin-binding protein originally isolated from vascular smooth muscle and has been reported to suppress bone formation. We are therefore curious how CNh1 is involved in bone loss that is caused by space flight in microgravity. We assessed the effects of tail suspension (TS) in C57BL/6J wild $\left(\mathrm{CN}^{++}\right)$and $\mathrm{CNh} 1$-deleted $\left(\mathrm{CN}^{--}\right)$mice to elucidate the role of $\mathrm{CNh} 1$ in bone loss under weightless conditions. Bone mineral density (BMD) of tibiae was measured by single energy X-ray absorptiometry, and bone volume fraction (BV/TV), mineral apposition rate (MAR), and bone formation rate (BFR/BS) were measured by bone histomorphometry. BMD, BV/TV, MAR, and BFR/BS were lower in $\mathrm{CN}^{+/+}$mice with TS than in those without. In the $\mathrm{CN}^{-/}$group, however, the decrease in each of these parameters by TS was ameliorated. Decreases in serum osteocalcin levels by TS in $\mathrm{CN}^{+/+}$mice were attenuated in $\mathrm{CN}^{-/-}$mice. Furthermore, urinary deoxypyridinolin (DPD), an indicator of bone resorption, was increased in $\mathrm{CN}^{+/+}$mice following TS, but not in $\mathrm{CN}^{-/}$mice. In transfection experiments, the degree of induction of bone formation markers, alkaline phosphatase (ALP) activity and bone morphogenetic protein (BMP)-4 mRNA expression, under stimulation with BMP-2, was lower in MC3T3-E1 mouse osteoblast-like cells expressing CNh1 than that in mock transfected cells. Notably, the BMP-2-induced ALP activity was decreased by CNh1 expression, which was partially rescued by treatment with the Rho kinase inhibitor Y27632. Taken together, these results indicate that $\mathrm{CNh} 1$ is responsible for weightlessness-induced bone loss in part through Rho signaling pathway.

Keywords: calponin h1; tail-suspension; bone loss; ALP; Rho

Tohoku J. Exp. Med., 2010, 221 (3), 221-227. C 2010 Tohoku University Medical Press

The balance of bone resorption and formation is regulated not only by hormones and cytokines, but also by mechanical stimuli. Reduced mechanical loading of bones during long-term bed rest or space flight in microgravity environments has been shown to cause rapid bone loss through enhanced bone resorption in the early phase and reduced bone formation over the period of weightlessness (Vico et al. 1998; Kim et al. 2003). Conversely, increased mechanical bone loading by strenuous exercise raises bone mass and strength (Forwood and Burr 1993; Turner and Robling 2005).

Mechanical signals to bones are introduced to osteoblasts or osteocytes through integrins, which function as mechano-sensing receptors (Aarden et al. 1996; GluhakHeinrich et al. 2003). The intracellular domains of integrin bind to several linker proteins, including $\alpha$ actinin, vinculin, and talin, and anchor to the cytoskeleton of actin micro-fila- ments, also referred to as stress fibers (highly polymerized and bundled actin fibers) (Loster et al. 2001; Zamir and Geiger 2001). Application of fluid shear to osteoblasts developed stress fibers and focal adhesions, and recruited $\beta 1$-integrins and $\alpha$-actinin into focal adhesions (Pavalko et al. 1998). Fluid shear also increased expression of both c-Fos and cyclooxygenase- 2 . These responses play a critical role in transducing mechanical signals applied at the cell surface into intracellular signals that are necessary for increased gene expression and new bone formation (Pavalko et al. 1998). Polymerization of actin is regulated by actinassociated proteins, such as non-phosphorylated calponin h1 (CNh1) (Kaneko et al. 2000), calmodulin (Yuan et al. 2008), and Rho family proteins (Burridge and Wennerberg 2004).

CNh1 is an actin-associated protein originally cloned from smooth muscle (Takahashi et al. 1988) that is assumed

Received April 14, 2010; revision accepted for publication May 25, 2010. doi:10.1620/tjem.221.221

Correspondence: Michiko Takeoka, Ph.D., Department of Molecular Oncology, Institute on Aging and Adaptation, Shinshu University

Graduate School of Medicine, 3-1-1 Asahi, Matsumoto 390-8621, Japan.

e-mail: takeokam@shinshu-u.ac.jp 
to stabilize polymerized actin filaments in its non-phosphorylated form. CNh1 is also found in osteoblasts, potentially functioning as a negative regulator of new bone formation. This potential function of CNh1 stems from analyses of the phenotypes of CNh1-deleted mice $\left(\mathrm{CN}^{-/-}\right)$, where mutant mice showed enhanced membranous bone formation in their developmental stage, resulting in thicker long bones at birth. In the postnatal stage, enhanced fracture repair and higher responsiveness to bone morphogenetic protein-2 (BMP-2) without changes in longitudinal bone growth were noted (Yoshikawa et al. 1998).

In order to elucidate the involvement of $\mathrm{CNh} 1$ in bone loss under weightless conditions, the effects of TS on bone loss, bone histomorphometry, and bone metabolic markers in the hind limbs of $\mathrm{CN}^{-/-}$and wild mice $\left(\mathrm{CN}^{+/+}\right)$were quantitatively analyzed, and the in vitro effects of $\mathrm{CNh} 1$ expression were examined in CNh1-transfected cells.

\section{Materials and Methods}

\section{Generation of CNh1-deleted mice}

The $\mathrm{CN}^{-/-}$mice used in the present study were generated from the same animal line used in previous studies (Yoshikawa et al. 1998; Taniguchi et al. 2001; Masuki et al. 2003; Taniguchi 2005) that were backcrossed to a C57BL/6J genetic background for at least eight generations. Eight-week-old male $\mathrm{CN}^{+/+}$and $\mathrm{CN}^{-/-}$mice (12 mice each) weighing 20-30 g were randomly assigned into 2 sets of 2 groups ( $n=$ 6 each) for loaded control and unloaded tail suspension (TS) studies.

\section{Tail suspension model}

Skeletal unloading was achieved using the TS model as previously described (Sakata et al. 1999). Briefly, a strip of elastic tape was applied to the surface of the tail. A clip at the end of the tape was fastened to an overhead bar and adjusted to maintain the mice at a 30-degree head-down tilt with the hind limbs elevated above the floor of the cage. The mice were subjected to TS for 4 weeks. Loaded control mice were housed individually in similar conditions, but without TS. Later, the mice were injected intraperitoneally with tetracycline $(4 \mathrm{mg} / \mathrm{kg})$ at 4 and 2 days before sacrificing at 4 weeks. This study was carried out in accordance with the Guidelines for Animal Care and Experimentation of the Shinshu University School of Medicine.

$X$-ray and single energy X-ray absorptiometry (SXA)

All tibiae were radiophotographed with a soft X-ray apparatus (Sofron Co., Ltd., Tokyo, Japan). To measure bone quality and tibia mass, the bone mineral density (BMD, $\mathrm{mg} / \mathrm{cm}^{2}$ ) of each tibia was measured by SXA using a bone mineral analyzer (DCS-600R, Aloka Co., Tokyo).

\section{Bone histomorphometry}

Specimen images observed under fluorescence were processed with a plotter (Cosmozone 1SA, Nikon, Japan). Bone volume (BV/ $\mathrm{TV}, \%$ ), mineral apposition rate (MAR, $\mathrm{mm} / \mathrm{day}$ ), and bone formation rate/BS (BFR/BS, $\mathrm{mm}^{3} / \mathrm{mm}^{2} /$ day) were calculated using total tissue volume $\left(\mathrm{TV}, \mathrm{mm}^{2}\right)$, bone volume $\left(\mathrm{BV}, \mathrm{mm}^{2}\right)$, and bone surface (BS, $\mathrm{mm}$ ) measurements.

\section{Bone metabolism markers}

Serum and urine were collected after 4 weeks TS period, just before sacrificing. Serum osteocalcin, an indicator of bone formation, was measured by using the assay system of BGP IRMA Mitsubishi (Mitsubishi Chem Corp., Tokyo, Japan). Urinary deoxypyridinoline (DPD), an indicator of bone resorption, was measured with an Osteolinks-DPD kit, a diagnostic enzyme immunoassay ELISA kit (Sumitomo, Osaka, Japan). Duplicate values for all biochemical measurements were obtained.

\section{DNA transfection}

The MC3T3-E1 mouse osteoblast-like cell line was obtained from Riken Bioresource Center (Tsukuba, Japan) and cultured in Minimum Essential Medium Alpha Medium (GibcoBRL, CA) supplemented with $10 \%$ fetal bovine serum (FBS, Sigma Chemical Co., St. Louis, $\mathrm{MO}$ ) and $1 \%$ antibiotic solution at $37^{\circ} \mathrm{C}$ in $5 \% \mathrm{CO}_{2}$ air.

Murine CNhl cDNA was cloned into the BamHI and HindIII cleavage sites of a pcDNA3.1(-)/myc-His A,B,C vector (Invitrogen) and transfected into MC3T3-E1 cells by the calcium phosphate precipitation method using a Mammalian Transfection Kit (Stratagene, La Jolla, CA).

\section{Western blotting}

For western blotting experiments, rabbit anti-mouse CNh1 antibody ( $\times 500$ dilution) (Yoshikawa et al. 1998) and AP-conjugated antirabbit IgG (1:1000, Promega, Madison, WI) were used as primary and secondary antibodies, respectively. Antibody binding was visualized with Nitro blue tetrazolium (Sigma, St. Louis, MO) and 5-Bromo-4chloro-3-indolyl phosphate (Sigma).

\section{Reverse transcription-polymerase chain reaction (RT-PCR) analysis}

RT-PCR was performed with a RNA PCR Kit (TaKaRa, Ohtsu, Japan). The primers used were sense 5 '-GAAAGGGGCTTCCACCG TATAAACA-3' and anti-sense 5'-ATCGGCTAATCCTGAC ATGCTGGCC-3' for mouse BMP-4, and sense 5'-AAGGGCGCA ACATCATTGGGCT-3' and anti-sense 5'- TCACAGTTGCCATGT AGACC-3' for GAPDH.

\section{Assay for alkaline phosphatase (ALP)}

Aliquots of recombinant human (rh) BMP-2 donated by Astellas Pharma Inc. (Tokyo, Japan) were used to stimulate ALP (Takuwa et al. 1991). After 24 hours of rhBMP-2 (30 ng/ml) exposure, cells were sonicated in $0.3 \mathrm{ml}$ of $0.5 \% \mathrm{NP}-40$ containing $1 \mathrm{mM} \mathrm{MgCl} \mathrm{ma}_{2}$ and 10 $\mathrm{mM}$ Tris (pH 7.5). Supernatants of the cell lysates were used for the enzyme assay. ALP activity was assayed using a test kit (Iatron Lab., Inc., Tokyo, Japan) with phenylphosphate as a substrate, expressed in King-Armstrong (KA) units, and normalized to the protein content of the sample.

\section{Treatment of cells with Rho kinase inhibitor Y27632}

Vector only and CNh1-transfected cells were treated with 10 $\mathrm{mM}$ of the Rho kinase inhibitorY27632 30 minutes before exposure to rhBMP-2 $(30 \mathrm{ng} / \mathrm{ml})$. ALP in the cultured medium was measured 24 hours after rhBMP-2 exposure.

\section{Statistical analysis}

The Mann-Whitney $U$ test was used for statistical analysis between two values using Stat View 5.0 software (SUS Institute, Inc., Berkley, CA). All values were expressed as the mean \pm standard error 
of the mean. $P<0.05$ was considered to be statistically significant.

\section{Results}

\section{Radiographic analyses}

The length, width, and mean total BMD SXA findings of the tibiae were virtually identical between $\mathrm{CN}^{-/-}$and $\mathrm{CN}^{+/+}$mice. All $\mathrm{CN}^{-/-}$mice with TS $(\mathrm{TS}+, n=6)$ and without TS (TS-, $n=6)$ and $\mathrm{CN}^{+/+}$mice with TS (TS+, $n=6$ ) and without TS (TS-, $n=6$ ) completed the experimental protocols. Representative X-ray pictures of the tibiae from each group harvested at the 4-week experimental endpoint are presented in Fig. 1A. The radiological density of the proximal tibiae of $\mathrm{CN}^{+/+} \mathrm{TS}+$ mice was visibly reduced compared with that of $\mathrm{CN}^{+/+}$TS- mice (Fig. 1A). The tibiae of the $\mathrm{CN}^{-/-}$mice, however, did not show such a reduction in radio-density after TS (Fig. 1A). Bone growth of the hind limbs was not affected by TS in either $\mathrm{CN}^{-/-}$or $\mathrm{CN}^{+/+}$ mice. The BMD of the tibiae obtained from $\mathrm{CN}^{+/+} \mathrm{TS}+$ mice $(84.1 \pm 4.3 \%)$ was significantly lower than that of $\mathrm{CN}^{+/+} \mathrm{TS}-$ mice $(100.0 \pm 5.5 \%, p<0.05)$ when expressed as a percentage (Fig. 1B). In the $\mathrm{CN}^{-/-}$groups, weightlessness-

A

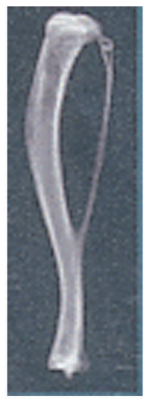

TS

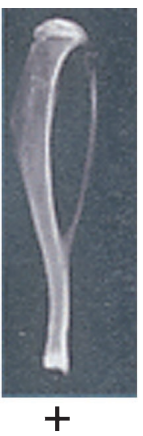

$\mathrm{CN}^{+/+}$

B

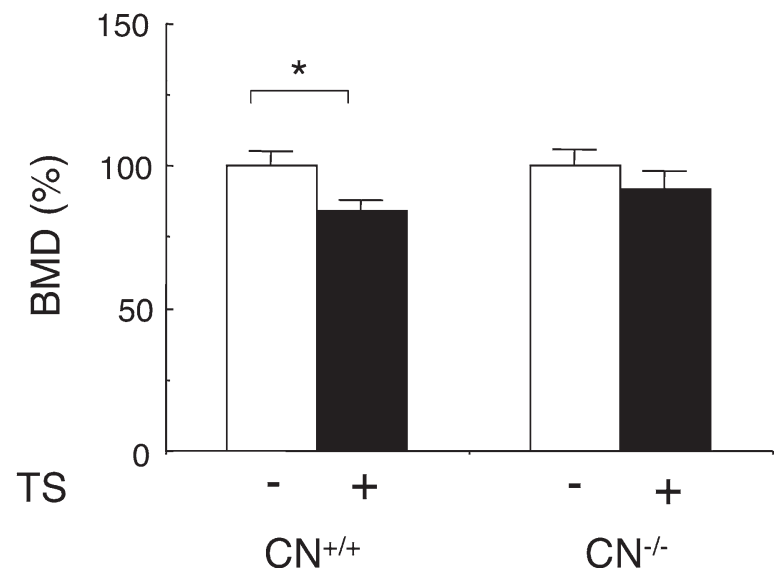

Fig. 1. Radiographic analyses.

A) Representative X-ray pictures of tibiae from respective mouse groups: $\mathrm{CN}^{+++}$wild mice with TS (TS+, $n=6$ ) and without TS (TS-, $n=6$ ), and $\mathrm{CN}^{-1-}$ mice with TS (TS+, $n=6$ ) and without TS (TS-, $n=6$ ). B) BMD of the tibiae obtained by SXA analysis of each of the four groups. induced bone loss was not significant $\left(\mathrm{CN}^{-/-} \mathrm{TS}-:\right.$ : $100.0 \pm$ $5.8 \% ; \mathrm{CN}^{-/} \mathrm{TS}+: 92.2 \pm 5.9 \%$, Fig. $1 \mathrm{~B}$ ).

\section{Bone histomorphometry}

Histomorphometric parameters were assessed in undecalcified sections of the proximal tibiae from the respective mice groups. BV/TV (\%), MAR (\%), and BFR/BS (\%), all of which parameters of bone formation, were significantly reduced in the $\mathrm{CN}^{+/+} \mathrm{TS}+$ group compared with control $\mathrm{CN}^{+/+} \mathrm{TS}-$ mice, indicating reduced bone formation in the hind limb bones of TS+ mice $\left[\mathrm{CN}^{+/ t} \mathrm{TS}-:\right.$ : $100.0 \pm 16.5$ for $\mathrm{BV} / \mathrm{TV}, 100.0 \pm 7.0$ for MAR, and $100.0 \pm 11.6$ for BFR/ $\mathrm{BS} ; \mathrm{CN}^{+/+} \mathrm{TS}+: 60.0 \pm 13.4$ for BV/TV, $80.4 \pm 5.1$ for MAR $(p<0.05)$, and $60.6 \pm 12.0$ for BFR/BS $(p<0.05)]$ (Fig. $2 \mathrm{~A}, \mathrm{~B}, \mathrm{C}$, left). In the $\mathrm{CN}^{-/-}$mice, the reduction of these parameters by TS was ameliorated, and no statistically significant reductions were noted (Fig. 2A, B, C, right). These results suggested improved bone loss due to preserved bone formation capacity in the hind limb bones under the microgravity conditions generated by TS.

A

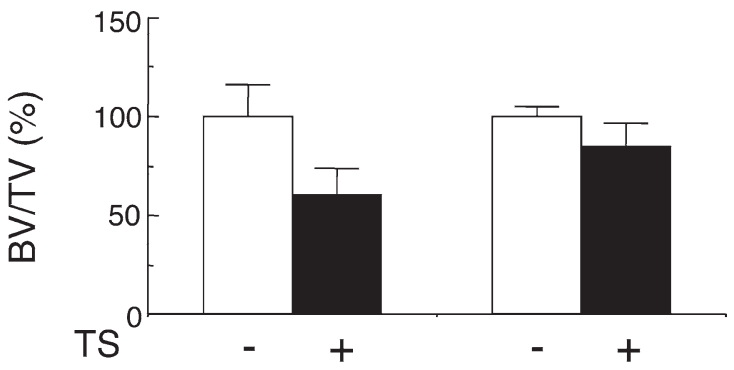

B

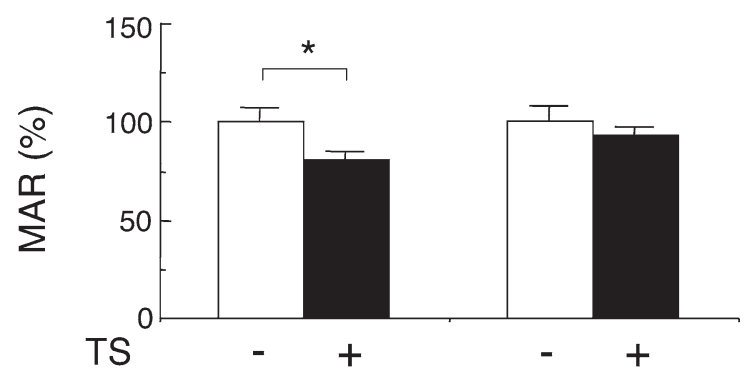

C

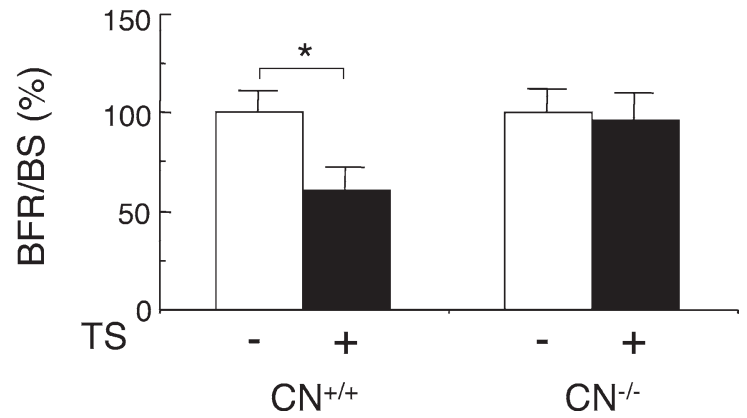

Fig. 2. Bone histomorphometry.

Bone histomorphometric parameters of undecalcified sections of the proximal tibiae from the respective four groups as indicated in Fig. 1. ${ }^{*} p<0.05$ 

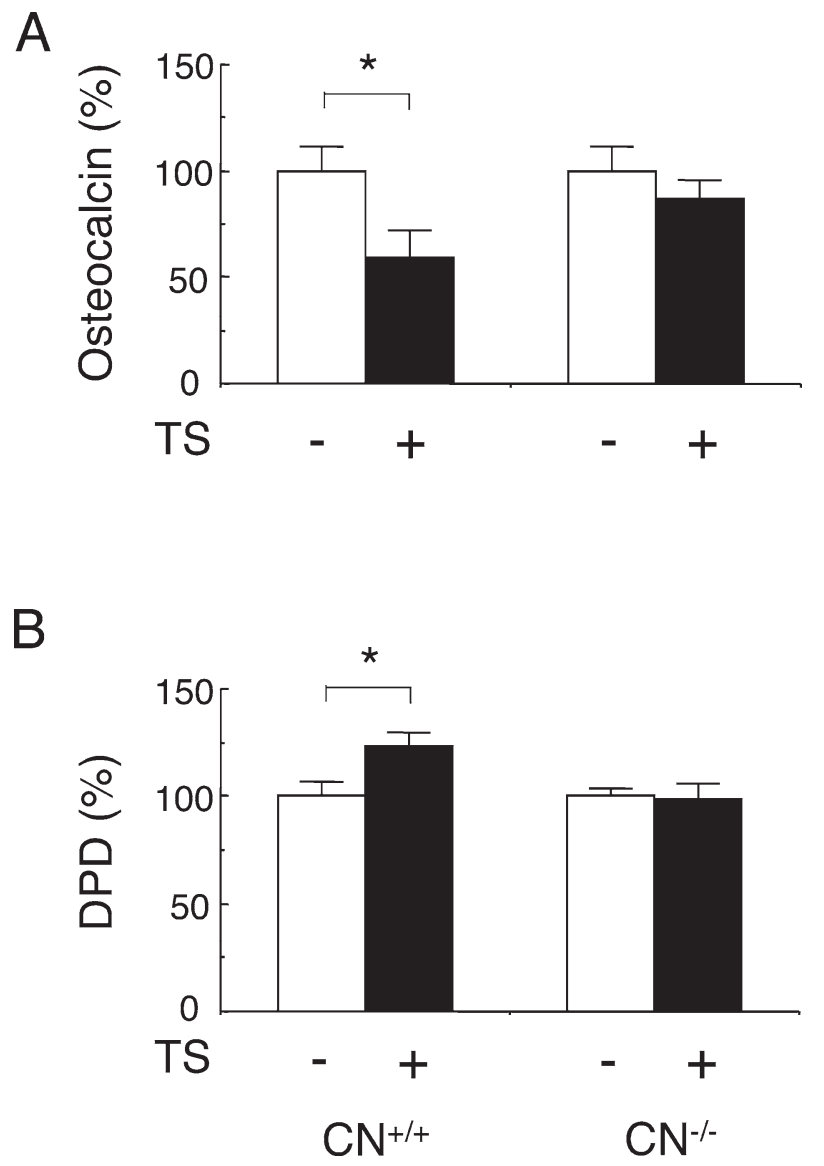

Fig. 3. Bone metabolism markers.

A) Bone formation activity as evaluated by serum osteocalcin level (\%) from the respective four groups as indicated in Fig. 1. B) Bone resorption activity as evaluated by DPD (\%) from the respective four groups of mice. $* p<0.05$

\section{Bone metabolism markers}

Bone formation activity as evaluated by serum osteocalcin levels (\%) was significantly reduced in $\mathrm{CN}^{+/+}$mice following TS $(100.0 \pm 11.6$ for TS-, $59.2 \pm 12.7$ for TS+, $p<0.05)$, whereas this reduction was slight in the $\mathrm{CN}^{-/}$ group under the same conditions $(100.0 \pm 11.6$ for TS-, 86.4 \pm 9.6 for TS+, Fig. 3A). Bone resorption activity as evaluated by DPD (\%) was significantly increased in the $\mathrm{CN}^{+++}$ group after TS $(100.0 \pm 6.8$ for TS-, $123.2 \pm 26.5$ for TS+, $p<0.05$ ), but no difference was observed between TS+ and TS- mice in the $\mathrm{CN}^{-/-}$group $(100.0 \pm 3.6$ for TS,- , $98.8 \pm 6.9$ for TS+, Fig. 3B).

\section{Transfection experiments}

Mouse CNh1 cDNA was cloned into a pcDNA3.1(-)/ myc-His A,B,C vector as indicated in Fig. 4A. Vector only or CNh1 expression vector was introduced into MC3T3-E1 cells, and expression of $\mathrm{CNh} 1$ was confirmed by western blotting (Fig. 4B).

To investigate the effect of exogenously expressed $\mathrm{CNh} 1$ on cellular responsiveness to rhBMP-2, ALP activity and BMP-4 mRNA expression were measured. ALP activi- ty was significantly suppressed in CNh1 transfectants $(3.9 \pm$ $0.5 \mathrm{KA}$ unit/mg protein) compared to vector transfectants $(8.8 \pm 1.2 \mathrm{KA}$ unit/mg protein, $p<0.01$, Fig. $5 \mathrm{~A})$. Induction of BMP-4 mRNA expression by rhBMP-2 was also suppressed in CNh1 transfectants, as judged by RT-PCR (Fig. 5B). Interestingly, the rhBMP-2-induced ALP activity was significantly lower in $\mathrm{CNh} 1$ transfectants $(3.3 \pm 0.2 \mathrm{KA}$ unit/mg protein) compared to vector transfectants $(10.2 \pm 0.4$ KA unit/mg protein, $p<0.01$ ) (Fig. 6), but the degree of the decrease was partially rescued by treatment with the Rho kinase inhibitor Y-27632 (5.2 $\pm 0.3 \mathrm{KA}$ unit/mg protein, $p<$ $0.05)$.

\section{Discussion}

Bone formation was reported to be systemically enhanced in mice lacking the $C N h l$ gene during intrauterine development, indicating a potential suppressor function of CNh1 on bone formation (Yoshikawa et al. 1998). Therefore, we speculated a possible involvement of $\mathrm{CNh} 1$ in weightlessness-induced bone loss and, as expected, the bone loss caused by 4 weeks of continuous TS was significantly ameliorated in $\mathrm{CN}^{-/-} \mathrm{TS}$ mice compared to controls.

In the paper of Yoshikawa et al. (1998), the number of activated periosteal osteoblasts in CNh1-deleted mice femur cortical bones was increased compared with that of wildtype mice. In our experiment, however, this difference was not observed in tibia, unexpectedly. One of the reasons may be the difference derived from the number of backcrossed generations. Compared to their mice, mice used in our experiment were at $8^{\text {th }}$ generation. Background was almost replaced to C57BL/6 mice. Further, histological difference in trabecular bone structure between $\mathrm{CN}^{+/+} \mathrm{TS}-$ and $\mathrm{CN}^{+/+} \mathrm{TS}+$ mice was too small to be detected, although some parameters indicated in our experiments significantly altered with TS.

Classical animal experimental results have shown that the predominant cause of bone loss in animals under weightless conditions was suppressed bone formation rather than enhanced bone resorption (Wronski et al. 1987), although the exact mechanism of this phenomenon has not yet been clarified. In our present study, bone resorption activity as evaluated by DPD (\%) was increased in the $\mathrm{CN}^{+/+}$ group after TS, but not in the $\mathrm{CN}^{-/-}$group. This result suggests that ameliorated bone loss is not only due to sustained bone formation but also to unchanged bone resorption, although further collection of resorption marker data is required.

In order to obtain clues on approaching the mechanism of $\mathrm{CNh} 1$ action, changes in gene expression due to $\mathrm{CNh} 1$ were investigated in CNh1-overexpressing MC3T3-E1 osteoblasts. In our in vitro experiments, BMP-4 stimulated by rhBMP-2 was suppressed by CNh1 transfection under normal conditions. Similarly, an enhanced response of BMP-4 in $\mathrm{CN}^{-/-}$mice was reported by Yoshikawa et al. (1998), who estimated that enhanced BMP responsiveness in cells may promote periosteal bone formation in $\mathrm{CN}^{-/}$ 


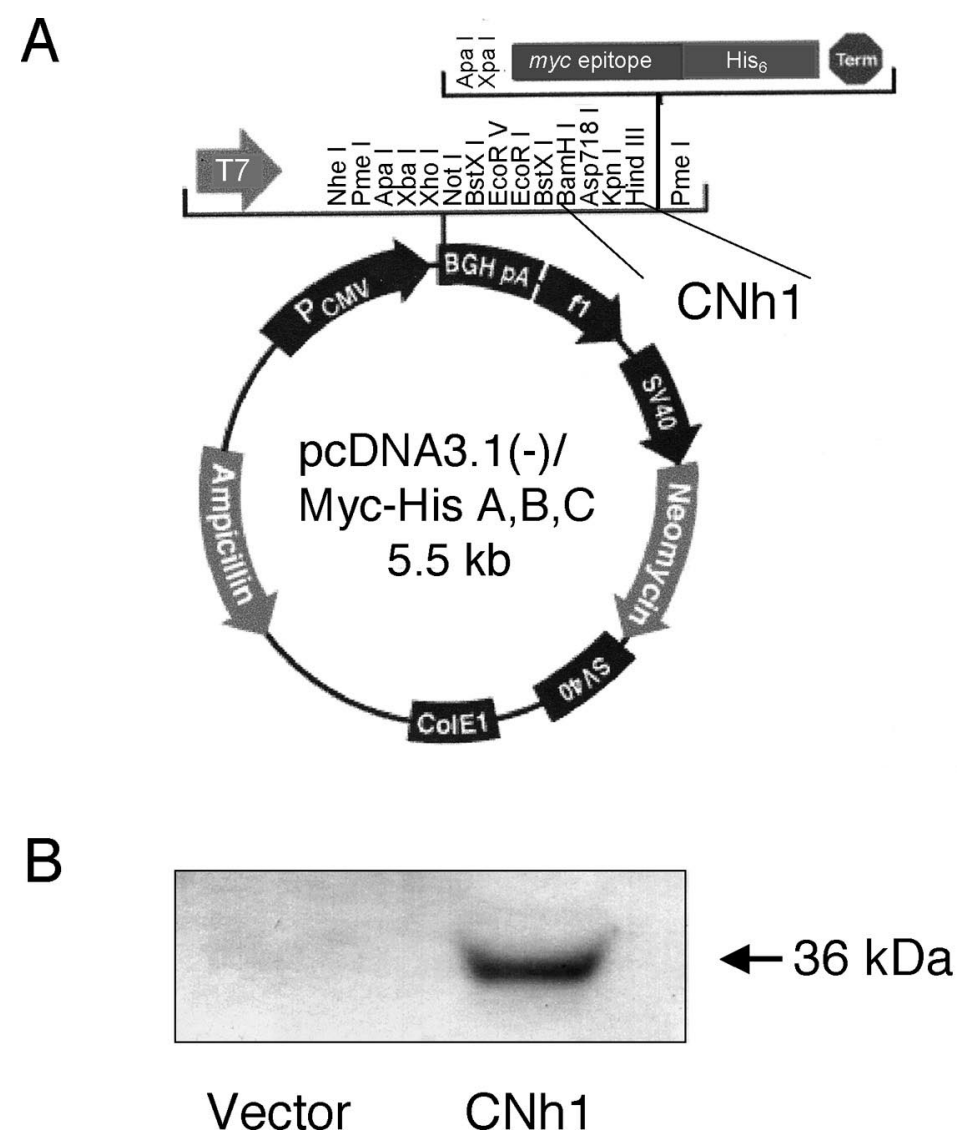

Fig. 4. Transient expression of CNh1.

A) Mouse calponin h1 (CNh1) cDNA was cloned into a pcDNA3.1(-)/myc-His A, B, C vector. B) MC3T3-E1 cells were transfected with vector only or CNh1-expression vector, and expression of CNh1 was confirmed in CNh1-transfectants by western blotting.

mice by stimulating the growth and recruitment of osteoblasts from the local undifferentiated mesenchymal cell pool.

According to Harmey et al. (2004), Rho-Rho-kinase inhibitors stimulate osteoblast differentiation and bone nodule formation correlating with increased BMP-2 and BMP-4 expression. Yoshikawa et al. (2009), also reported that Y-27632 enhanced ectopic bone formation induced by rhBMP-2 impregnated into an atelocollagen carrier in mice and also enhanced the osteoblastic differentiation of cultured murine neonatal calvarial cells, associated with increased expression of BMP-4 gene. A constitutively active mutant of Rho kinase attenuated osteoblastic differentiation and the Rho kinase inhibitor reversed this phenotype. Thus, Rho kinase inhibits osteogenesis, and a Rho kinase inhibitor in combination with the local delivery of rhBMP/collagen composite may be clinically applicable for stimulating bone formation (Yoshikawa et al. 2009). In our experiment, ALP was significantly suppressed by CNh1 transfection, but was partially rescued by treatment with Y27632, a Rho kinase inhibitor. CNh1 is a substrate of Rho-kinase, and the phosphorylated form of CNh1 cannot interact with actin (Kaneko et al. 2000). Since Y27632 par- tially restored the expression of ALP suppressed by CNh1, the phosphorylated form of CNh1 may be involved in the inhibition of bone differentiation while non-phosphorylated CNh1 might enhance bone differentiation or formation through its stabilizing ability on actin filaments.

Recently CNh1 was reported to play a major role in the stabilization of actin stress fibers, and the expression of CNh1 was up-regulated by the treatment with transforming growth factor (TGF)- $\beta$ (Dykes and Wright 2007; Li et al. 2007). The involvement of TGF- $\beta$ in the interaction between Rho and CNh1 (Chen et al. 2006) directs our study to TGF- $\beta$. Taken together, TGF- $\beta$ may be one of the targets of molecular interaction of CNh1.

Lastly, it must be noted that we did not apply mechanical stretch to our in vitro experiments. Expression of CNh1 under stretch conditions is associated with actin polymerization and Rho activity (Albinsson et al. 2004) and mediated at least partially by regulation of Rho expression $(\mathrm{Qu}$ et al. 2008). Therefore, we believe we were able to address the involvement of CNh1 with Rho activity in bone loss under weightlessness in this study. 
A

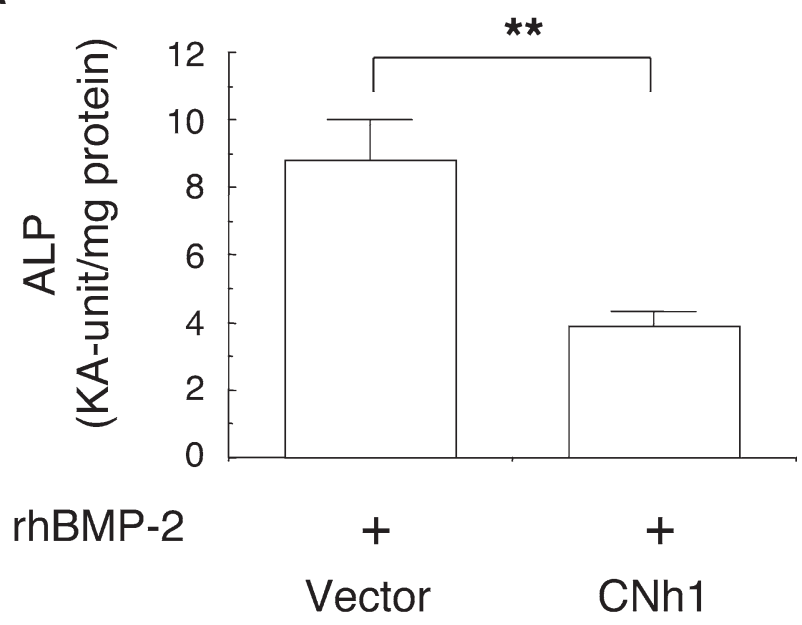

B

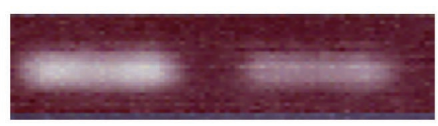

\section{GAPDH}

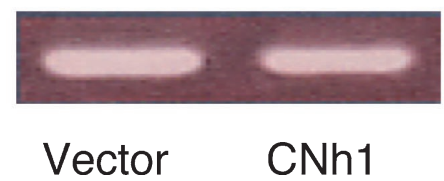

Fig. 5. Effect of $\mathrm{CNh} 1$ on bone formation markers in transfected cells.

A) Effect of CNh1 on ALP activity and cellular responsiveness to rhBMP-2. $* p<0.05$

B) Effect of CNh1 on induction of BMP-4 mRNA expression by rhBMP-2.

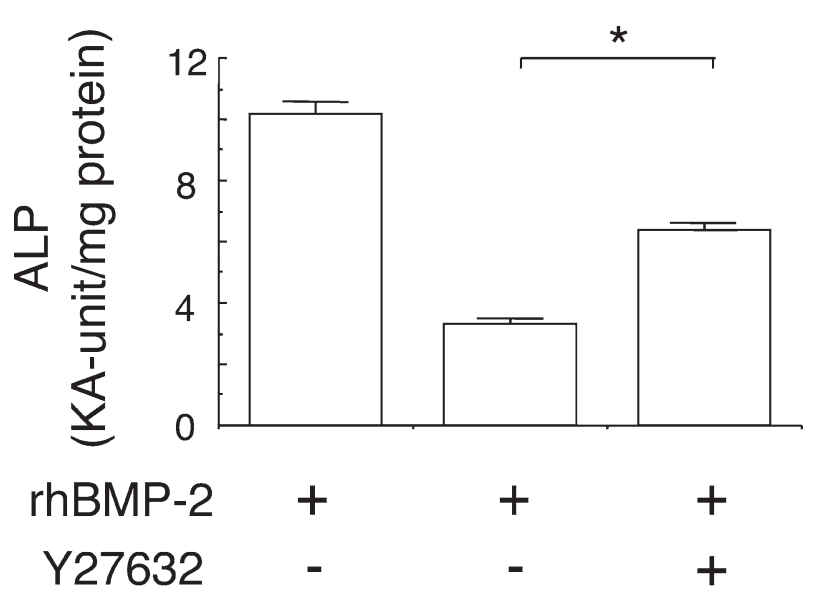

\section{Vector CNh1 CNh1}

Fig. 6. Effects of a Rho kinase inhibitor on ALP activity in CNh1-expressing cells.

Effects of the Rho kinase inhibitor Y27632 were analyzed on suppression of ALP activity in CNh1-expressing cells under rhBMP-2 stimulation. $N=6$ for the left and center columns and $n=4$ for the right column. ${ }^{* *} p<0.01, * p<$ 0.05

\section{Conclusion}

Since the degree of TS-induced bone loss was significantly attenuated in CNh1-deficient mice, the phosphorylated form of $\mathrm{CNh} 1$ might be a causative molecule in weightlessness-induced osteopenia, although the exact function of $\mathrm{CNh} 1$ in regulating mechanical signal transduction remains to be addressed. If CNh1 is indeed involved in the transduction, manipulation of the expression or function of CNh1 may lead to new modalities for bone loss prevention in severe systemic osteoporosis.

\section{Acknowledgments}

We thank Professor S. Taniguchi (Shinshu University Graduate School of Medicine) and Dr. K. Takaoka (previous professor of Graduate School of Medicine Osaka City University) for their helpful instruction and discussion. This work was supported by a Grant-in-Aid from the Japan Space forum, a nonprofit corporation.

\section{References}

Aarden, E.M., Nijweide, P.J., van der Plas, A., Alblas, M.J., Mackie, E.J., Horton, M.A. \& Helfrich, M.H. (1996) Adhesive properties of isolated chick osteocytes in vitro. Bone, 18, 305313.

Albinsson, S., Nordstrom, I. \& Hellstrand, P. (2004) Stretch of the vascular wall induces smooth muscle differentiation by promoting actin polymerization. J. Biol. Chem., 279, 3484934855 .

Burridge, K. \& Wennerberg, K. (2004) Rho and Rac take center stage. Cell, 116, 167-179.

Chen, S., Crawford, M., Day, R.M., Briones, V.R., Leader, J.E., Jose, P.A. \& Lechleider, R.J. (2006) RhoA modulates Smad signaling during transforming growth factor-beta-induced smooth muscle differentiation. J. Biol. Chem., 281, 17651770 .

Dykes, A.C. \& Wright, G.L. (2007) Down-regulation of calponin destabilizes actin cytoskeletal structure in A7r5 cells. Can. J. Physiol. Pharmacol., 85, 225-232.

Forwood, M.R. \& Burr, D.B. (1993) Physical activity and bone mass: exercises in futility? Bone Miner., 21, 89-112.

Gluhak-Heinrich, J., Ye, L., Bonewald, L.F., Feng, J.Q., MacDougall, M., Harris, S.E. \& Pavlin, D. (2003) Mechanical loading stimulates dentin matrix protein 1 (DMP1) expression in osteocytes in vivo. J. Bone Miner. Res., 18, 807-817.

Harmey, D., Stenbeck, G., Nobes, C.D., Lax, A.J. \& Grigoriadis, A.E. (2004) Regulation of osteoblast differentiation by Pasteurella multocida toxin (PMT): a role for Rho GTPase in bone formation. J. Bone Miner. Res., 19, 661-670.

Kaneko, T., Amano, M., Maeda, A., Goto, H., Takahashi, K., Ito, M. $\&$ Kaibuchi, K. (2000) Identification of calponin as a novel substrate of Rho-kinase. Biochem. Biophys. Res. Commun., 273, 110-116.

Kim, H., Iwasaki, K., Miyake, T., Shiozawa, T., Nozaki, S. \& Yajima, K. (2003) Changes in bone turnover markers during 14-day 6 degrees head-down bed rest. J. Bone Miner. Metab,, 21, 311-315.

Li, F., Luo, Z., Huang, W., Lu, Q., Wilcox, C.S., Jose, P.A. \& Chen, S. (2007) Response gene to complement 32, a novel regulator for transforming growth factor-beta-induced smooth muscle differentiation of neural crest cells. J. Biol. Chem., 282, 10133-10137.

Loster, K., Vossmeyer, D., Hofmann, W., Reutter, W. \& Danker, K. (2001) alpha1 Integrin cytoplasmic domain is involved in focal adhesion formation via association with intracellular proteins. Biochem. J., 356, 233-240. 
Masuki, S., Takeoka, M., Taniguchi, S., Yokoyama, M. \& Nose, H. (2003) Impaired arterial pressure regulation during exercise due to enhanced muscular vasodilatation in calponin knockout mice. J. Physiol., 553, 203-212.

Pavalko, F.M., Chen, N.X., Turner, C.H., Burr, D.B., Atkinson, S., Hsieh, Y.F., Qiu, J. \& Duncan, R.L. (1998) Fluid shearinduced mechanical signaling in MC3T3-E1 osteoblasts requires cytoskeleton- integrin interactions. Am. J. Physiol., 275, C1591-1601.

Qu, M.J., Liu, B., Qi, Y.X. \& Jiang, Z.L. (2008) Role of Rac and Rho-GDI alpha in the frequency-dependent expression of h1calponin in vascular smooth muscle cells under cyclic mechanical strain. Ann. Biomed. Eng., 36, 1481-1488.

Sakata, T., Sakai, A., Tsurukami, H., Okimoto, N., Okazaki, Y., Ikeda, S., Norimura, T. \& Nakamura, T. (1999) Trabecular bone turnover and bone marrow cell development in tail-suspended mice. J. Bone Miner. Res., 14, 1596-1604.

Takahashi, K., Hiwada, K. \& Kokubu, T. (1988) Vascular smooth muscle calponin. A novel troponin T-like protein. Hypertension, 11, 620-626.

Takuwa, Y., Ohse, C., Wang, E.A., Wozney, J.M. \& Yamashita, K. (1991) Bone morphogenetic protein-2 stimulates alkaline phosphatase activity and collagen synthesis in cultured osteoblastic cells, MC3T3-E1. Biochem. Biophys. Res. Commun., 174, 96-101.

Taniguchi, S. (2005) Suppression of cancer phenotypes through a multifunctional actin-binding protein, calponin, that attacks cancer cells and simultaneously protects the host from invasion. Cancer Sci., 96, 738-746.

Taniguchi, S., Takeoka, M., Ehara, T., Hashimoto, S., Shibuki, H.,
Yoshimura, N., Shigematsu, H., Takahashi, K. \& Katsuki, M. (2001) Structural fragility of blood vessels and peritoneum in calponin h1-deficient mice, resulting in an increase in hematogenous metastasis and peritoneal dissemination of malignant tumor cells. Cancer Res., 61, 7627-7634.

Turner, C.H. \& Robling, A.G. (2005) Mechanisms by which exercise improves bone strength. J. Bone Miner. Metab., 23, 16-22.

Vico, L., Lafage-Proust, M.H. \& Alexandre, C. (1998) Effects of gravitational changes on the bone system in vitro and in vivo. Bone, 22, 95S-100S.

Wronski, T.J., Morey-Holton, E.R., Doty, S.B., Maese, A.C. \& Walsh, C.C. (1987) Histomorphometric analysis of rat skeleton following spaceflight. Am. J. Physiol., 252, R252-255.

Yoshikawa, H., Taniguchi, S.I., Yamamura, H., Mori, S., Sugimoto, M., Miyado, K., Nakamura, K., Nakao, K., Katsuki, M., Shibata, N. \& Takahashi, K. (1998) Mice lacking smooth muscle calponin display increased bone formation that is associated with enhancement of bone morphogenetic protein responses. Genes Cells, 3, 685-695.

Yoshikawa, H., Yoshioka, K., Nakase, T. \& Itoh, K. (2009) Stimulation of Ectopic Bone Formation in Response to BMP-2 by Rho Kinase Inhibitor. Clin. Orthop. Relat. Res., 467, $3087-$ 3095.

Yuan, J., Shi, G.X., Shao, Y., Dai, G., Wei, J.N., Chang, D.C. \& Li, C.J. (2008) Calmodulin bound to stress fibers but not microtubules involves regulation of cell morphology and motility. Int. J. Biochem. Cell Biol., 40, 284-293.

Zamir, E. \& Geiger, B. (2001) Molecular complexity and dynamics of cell-matrix adhesions. J. Cell Sci., 114, 3583-3590. 